UCB (consultant, clinical trials, advisor), Christopher Edwards Grant/research support from: Abbvie, Biogen, Roche, Consultant of: Abbvie, Samsung, Speakers bureau: Abbvie, BMS, Biogen, Celgene, Fresenius, Gilead, Janssen, Lilly, Mundipharma, Pfizer, MSD, Novartis, Roche, Samsung, Sanofi, UCB, Elizabeth Hensor: None declared, Edward Vital Grant/research support from: AstraZeneca, Roche/ Genentech, and Sandoz, Consultant of: AstraZeneca, GSK, Roche/Genentech, and Sandoz, Speakers bureau: Becton Dickinson and GSK DOI: 10.1136/annrheumdis-2020-eular.2160

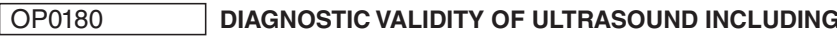 EXTRA-CRANIAL ARTERIES IN GIANT CELL ARTERITIS}

I. Monjo ${ }^{1}$, E. Fernández ${ }^{1}$, D. Peiteado ${ }^{1}$, A. Balsa ${ }^{1}$, E. De Miguel ${ }^{1} .{ }^{1}$ University Hospital La Paz, Rheumatology, Madrid, Spain

Background: Giant cell arteritis (GCA) is a chronic vasculitis of the medium and large arteries. The involvement of large vessel (LV) either isolated or associated with cranial artery is frequent, so it is necessary to use imaging techniques for diagnosis, because the biopsy in these cases is not useful. European League Against Rheumatism (EULAR) recommends an early imaging test in patients with suspected GCA, and ultrasound of temporal \pm axillary arteries is recommended as the first imaging modality in patients with suspected predominantly cranial GCA (1).

Objectives: To assess the validity of Colour Doppler ultrasound (CDUS) of temporal superficial arteries (TA) and LV (axillary, subclavian and carotid) in the diagnosis of GCA, using as gold standard the patient's definitive clinical diagnosis. Analyse if routine ultrasound examination of LV improves the diagnostic accuracy.

Methods: This was an observational, descriptive and analytical study of 198 consecutive patients with GCA suspicion. A baseline CDUS of the TA and LV was performed. Ultrasound diagnosis was made according to the OMERACT (Outcome Measures in Rheumatology) definitions of halo sign and was established as a limit of average intimal thickness $\geq 0.34 \mathrm{~mm}$ for superficial temporal arteries and $\geq 1 \mathrm{~mm}$ for axillary, subclavian and carotid arteries. Statistical analysis was performed using SPSS version 25

Results: Eighty-seven patients (43.9\%) were CDUS compatible with GCA, and 111 patients $(56.1 \%)$ had a negative CDUS. Among the patients with positive CDUS three different patterns were detected: 45 patients $(51.7 \%)$ had an exclusive cranial involvement, $31(35.6 \%)$ had a mixed pattern with involvement of both TA and LV and 11 (12.6\%) had an exclusive LV involvement. The validity (sensitivity and specificity) and security (positive predictive value and negative predictive value) of diagnostic are shown in table.

When we analyse patients with LV involvement, $87.8 \%$ have axillary artery involvement, $77.4 \%$ subclavian involvement and $34.4 \%$ carotids involvement. If we only explored the axillary arteries, $12.2 \%$ of patients with LV involvement would not be diagnosed. However, if we explored axillary and subclavian arteries, $100 \%$ of patients with LV involvement would be diagnosed.

Conclusion: Half of the patients with GCA have LV involvement and up to $12.8 \%$ exclusively LV affectation in our series. Adding CDUS exploration of LV arteries to TA increases both sensitivity and diagnostic specificity. The minimum ultrasound examination of LV should include both axillary and subclavian arteries. References:

[1] Dejaco C, Ramiro S, Duftner C, et al. EULAR recommendations for the use of imaging in large vessel vasculitis in clinical practice. Ann Rheum Dis. 2018;77(5):636-3

\begin{tabular}{lcccc}
\hline & Sensitivity & Specificity & $\begin{array}{c}\text { Positive } \\
\text { predictive value }\end{array}$ & $\begin{array}{c}\text { Negative } \\
\text { predictive value }\end{array}$ \\
\hline CDUS TA and LV & $97,7 \%$ & $97,3 \%$ & $96,6 \%$ & $98,2 \%$ \\
CDUS TA & $83,9 \%$ & $97,3 \%$ & $96,1 \%$ & $88,5 \%$ \\
\hline
\end{tabular}

Disclosure of Interests: Irene Monjo: None declared, Elisa Fernández: None declared, Diana Peiteado: None declared, Alejandro Balsa Grant/research support from: BMS, Roche, Consultant of: AbbVie, Gilead, Lilly, Pfizer, UCB, Sanofi,
Sandoz, Speakers bureau: AbbVie, Lilly, Sanofi, Novartis, Pfizer, UCB, Roche, Nordic, Sandoz, Eugenio de Miguel Grant/research support from: Yes (Abbvie Novartis, Pfizer), Consultant of: Yes (Abbvie, Novartis, Pfizer), Paid instructo for: yes (AbbVie, Novartis, Pfizer, MSD, BMS, UCB, Roche, Grunental, Janssen, Sanofi), Speakers bureau: yes (AbbVie, Novartis, Pfizer, MSD, BMS, UCB Roche, Grunental, Janssen, Sanofi) DOI: 10.1136/annrheumdis-2020-eular.5036

\section{OP0181 FUNCTIONAL CUT-OFFS TO DISTINGUISH PULMONARY VASCULAR AND PARENCHYMAL INVOLVEMENT IN SYSTEMIC SCLEROSIS (SSC): A QUANTITATIVE ANALYSIS OF IMAGING FEATURES AT CHEST COMPUTED TOMOGRAPHY (CT)}

C. Bruni ${ }^{1}$, M. Occhipinti ${ }^{2,3}$, G. Camiciottoli ${ }^{3}$, M. Bartolucci ${ }^{4}$, G. Lepri ${ }^{1}$,

A. Fabbrizzi ${ }^{3}$, A. Tottoli ${ }^{1}$, A. Bassetto ${ }^{3}$, G. Ciardi ${ }^{3}$, D. Giuggioli ${ }^{5}$, G. Cuomo ${ }^{6}$, F. Masini ${ }^{6}$, F. Lavorini ${ }^{3}$, L. Calistri ${ }^{4}$, M. Matucci-Cerinic ${ }^{1} .{ }^{1}$ University of Florence, Rheumatology, Florence, Italy; ${ }^{2}$ University of Florence, Radiology, Firenze, Italy; ${ }^{3}$ University of Florence, Pulmonology, Firenze, Italy; ${ }^{4}$ Careggi University Hospital, Radiology, Firenze, Italy; ${ }^{5}$ Policlinico of Modena University Hospital of Modena, Rheumatology, Modena, Italy; ${ }^{6}$ University of Campania Studies "Luigi Vanvitelli", Napoli, Italy

Background: Interstitial lung disease (ILD) and pulmonary arterial hypertension represent the most frequent causes of morbidity and mortality in SSc, with chest CT representing the gold standard in ILD assessment, while FVC and DLco allow functional assessment.

Objectives: As qualitative analysis of given chest CT scans is hampered by low reproducibility, we aimed to perform a quantitative analysis (QA) of CT scans able to investigate the parenchymal and vascular features in SSc-ILD and thus testing the relationship with clinical-functional data.

Methods: We prospectively enrolled 80 patients who underwent PFTs and spirometry-gated chest CT scan at TLC on the same day. Clinical, lung functional and diffusion data, as well as disability indexes were collected. CT images were analyzed by a computational platform for texture analysis of ILD patterns (CALIPER) through Imbio LTA. It quantified the extent of normal lung $(\% \mathrm{~N})$, groundglass opacities (\%GG), reticulation (\%RET), honeycombing (\%HC), hyperlucent $(\% \mathrm{HL})$, absolute (PVV, $\mathrm{cm}^{3}$ ) and normalized (PVV/LV, \%) pulmonary vascular volumes. Cut-offs of normality for \%FVC and \%DLco of $80 \%$ and $70 \%$ were tested to differentiate parenchymal and vascular features.

Results: 73 patients/CT scans were eligible for both software analyses. CALIPER showed GG\% as the most frequent radiological pattern (mean $5.5 \pm 10.4 \%$ ). $\%$ FVC and \% TLC negatively correlated with all ILD patterns, while \%DLco with RET\% only; PVV and PVV/LV negatively correlated with \%FVC and \%TLC, while $\%$ DLco with PVV/LV only. Positive correlations were found between all ILD patterns and vascular volumes (Table 1)

\begin{tabular}{lccccccccc}
\hline & & LV $\left(\mathrm{cm}^{3}\right)$ & $\% \mathrm{~N}$ & $\% \mathrm{GG}$ & $\% \mathrm{RET}$ & $\% \mathrm{HC}$ & $\% \mathrm{HL}$ & $\mathrm{PVV}\left(\mathrm{cm}^{3}\right)$ & $\%$ PVV/LV \\
\hline $\mathrm{FVC} \%$ & $\mathrm{r}$ & .60 & -.19 & -.40 & -.34 & -.30 & .35 & -.26 & -.44 \\
& $\mathrm{p}$ & $<.001$ & - & $<.001$ & .004 & .01 & .003 & .04 & $<.001$ \\
$\mathrm{FEV}_{1} \%$ & $\mathrm{r}$ & .58 & -.02 & -.38 & -.25 & -.24 & .23 & -.35 & -.49 \\
& $\mathrm{p}$ & $<.001$ & - & .002 & .04 & .05 & - & .004 & $<.001$ \\
$\mathrm{FEV}_{1} / \mathrm{FVC}$ & $\mathrm{r}$ & -.16 & .33 & .22 & .16 & .21 & -.35 & -.15 & -.08 \\
& $\mathrm{p}$ & - & .02 & - & - & - & - & - & - \\
$\mathrm{TLC} \%$ & $\mathrm{r}$ & .71 & -.14 & -.42 & -.37 & -.48 & .40 & -.43 & -.64 \\
& $\mathrm{p}$ & $<.001$ & - & .001 & .01 & $<.001$ & .002 & $<.001$ & $<.02$ \\
DLCO\% & $\mathrm{r}$ & .38 & -.05 & -.21 & -.31 & -.22 & .30 & -.21 & -.33 \\
& $\mathrm{p}$ & .01 & - & - & .01 & - & - & - & .006 \\
FVC/DLCO & $\mathrm{r}$ & .03 & -.08 & -.06 & -.003 & -.09 & .08 & -.06 & -.08 \\
& $\mathrm{p}$ & - & - & - & - & - & - & - & - \\
\hline
\end{tabular}

Cut-offs equal to 80 for \%FVC and 70 for \%DLco distinguished both parenchymal and vascular features, while 80 for \%DLco characterized vascular features only. These results were confirmed also when patients were stratified according to absent/single/combined \%FVC and $\%$ DLCO impairments with $80 \%$ cut-offs (Table 2 ).

Conclusion: In SSc a cut-off at 80 for \%DLco may help identifying vascular changes as automatically assessed on chest CT scan, without any underlying

\begin{tabular}{|c|c|c|c|c|c|c|c|c|c|}
\hline & $\mathrm{FVC}<80 \%$ & $F V C \geq 80 \%$ & $p$ & DLco $<80 \%$ & DLco $\geq 80 \%$ & $p$ & DLco $<70 \%$ & DLco $\geq 70 \%$ & $p$ \\
\hline$\% \mathrm{~N}$ & $82.7(9.6)$ & $86.2(14.7)$ & - & $86.6(12.7)$ & $80.8(15.8)$ & - & $84.1(13.9)$ & $86.4(13.5)$ & - \\
\hline$\% G G$ & $10.3(8.9)$ & $2.4(3.9)$ & $<.001$ & $5.0(6.7)$ & $3.9(6.9)$ & - & $6.2(7.5)$ & $2.4(4.8)$ & .002 \\
\hline$\%$ RET & $2.9(2.9)$ & $0.8(1.3)$ & $<.001$ & $1.6(2.1)$ & $0.7(0.9)$ & - & $1.9(2.4)$ & $0.6(0.8)$ & .007 \\
\hline$\% \mathrm{HC}$ & $0.4(0.6)$ & $0.1(0.1)$ & $<.001$ & $0.2(0.3)$ & $0.1(0.1)$ & - & $0.2(0.4)$ & $0.05(0.2)$ & .010 \\
\hline$\% \mathrm{HL}$ & $3.6(6.8)$ & $8.9(12.1)$ & - & $5.4(8.8)$ & $14.1(15.4)$ & .050 & $6.3(10.1)$ & $9.2(12.7)$ & - \\
\hline PVV & $125.6(39.1)$ & $90.9(26.9)$ & $<.001$ & $101.9(34.8)$ & $84.7(19.4)$ & .016 & 106.9 (38.3) & $87.5(20.5)$ & .012 \\
\hline PVV/LV & $3.8(1.6)$ & $2.0(0.7)$ & $<.001$ & $2.51(1.3)$ & $1.7(0.6)$ & .002 & $2.76(1.4)$ & $1.83(0.6)$ & .001 \\
\hline
\end{tabular}


ILD. The $80 \%$ cut-off for $\%$ DLco may be proposed to identify isolated vascular involvement, while $\% \mathrm{FVC}$ at $80 \%$ or $\% \mathrm{DLco}$ at $70 \%$ to identify significant parenchymal involvement. These results need to be confirmed in larger multi-centric cohorts.

Disclosure of Interests: Cosimo Bruni Speakers bureau: Actelion, Eli Lilly, Mariaelena Occhipinti Consultant of: Imbio, Gianna Camiciottoli: None declared, Maurizio Bartolucci: None declared, Gemma Lepri: None declared, Alessio Fabbrizzi: None declared, Alessandra Tottoli: None declared, Anna Bassetto: None declared, Giuglia Ciardi: None declared, Dilia Giuggioli: None declared, Giovanna CUOMO: None declared, Francesco Masini: None declared, Federico Lavorini: None declared, Linda Calistri: None declared, Marco Matucci-Cerinic Grant/research support from: Actelion, MSD, Bristol-Myers Squibb, Speakers bureau: Acetelion, Lilly, Boehringer Ingelheim DOI: 10.1136/annrheumdis-2020-eular.2188

\section{OP0182 \\ PROTEOGLYCAN LOSS IN ARTICULAR CARTILAGE IS ASSOCIATED WITH JOINT INFLAMMATION SEVERITY IN PSORIATIC ARTHRITIS - A COMPOSITIONAL MAGNETIC RESONANCE IMAGING STUDY}

P. Sewerin ${ }^{1}$, D. Abrar ${ }^{2}$, S. Nebelung ${ }^{2}$, M. Frenken ${ }^{2}$, T. Ulrich ${ }^{2}$, K. L. Radke ${ }^{2}$, G. Antoch ${ }^{2}$, S. Vordenbäumen ${ }^{1}$, R. Brinks ${ }^{1}$, M. Schneider ${ }^{1}$, B. Ostendorf ${ }^{1}$, C. Schleich ${ }^{2}{ }^{1}$ Heinrich-Heine University, Department for Rheumatology, Duesseldorf, Germany; ${ }^{2}$ Heinrich-Heine University, Institut for Diagnostic and Interventional Radiology, Duesseldorf, Germany

Background: Even though cartilage loss is a known feature of psoriatic arthritis (PsA), little is known about its role in the pathogenesis of PsA. Using delayed gadolinium-enhanced magnetic resonance imaging of cartilage (dGEMRIC) as a non-invasive marker of the tissue's proteoglycan content, such early (i.e. pre-morphological) changes have been associated with inflammation in rheumatoid arthritis (RA). Yet, this association has not been studied before in PsA Objectives: Is the severity of local joint inflammation associated to local proteoglycan loss in PsA patients?

Methods: Metacarpophalangeal (MCP), proximal interphalangeal (PIP), and distal interphalangeal (DIP) joints of 17 patients with active PSA were evaluated by high-resolution clinical standard morphological and dGEMRIC sequences using a 3T MRI scanner (Magnetom Skyra, Siemens) and a dedicated 16-channel hand coil. Images were analyzed by two independent raters for dGEMRIC indices, PsA MRI scores (PsAMRIS) and total cartilage thickness (TCT). Kendall-Tau correlation coefficients $(\tau)$ were calculated.

Results: We found significant negative correlations between dGEMRIC indices and total PSAMRIS $(\tau=-0.5, p=0.012)$, synovitis $(\tau=-0.56, p=0.006)$, flexor tenosynovitis $(\tau=-0.4, p=0.049)$, and periarticular inflammation $(\tau=-0.72, p<$ 0.001 ). Significant positive correlations were found between TCT and dGEMRIC indices in all joint levels $(\tau=0.43, p<0.001)$. No significant correlations were determined between dGEMRIC indices and bone erosion, bone edema or bone proliferation.

Conclusion: In PsA, proteoglycan loss as assessed by dGEMRIC is associated with periarticular inflammation, synovitis, and flexor tenosynovitis, but not with bone erosion or proliferation, thereby highlighting the need for effective anti-inflammatory treatment regimes. Beyond morphology, advanced MRI techniques may be used to assess cartilage composition in PsA and to identify early

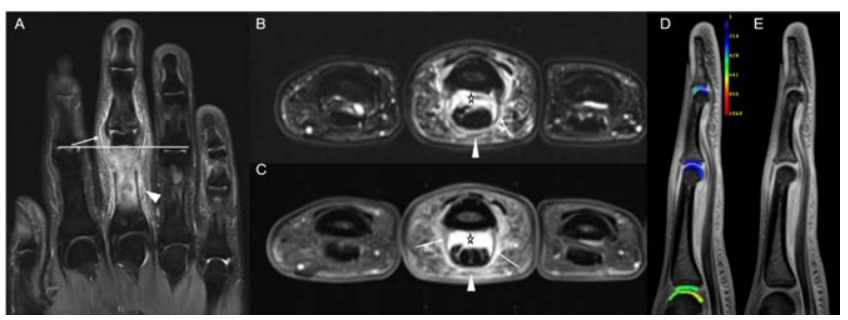

Figure 1 Right hand of a 26-year-old male with psoriatic arthritis Coronal STIR image (A) of digits 1-5, transversal fat-saturated (fS) T2-weighted image of digits 2-4 (B) and the corresponding transversal fs contrast-enhanced T1-weighted image (C) at the distal portion of the proximal phalanges. Horizontal white bar in (A) indicates level of transversal slices (B) \& (C). Sagittal fs Proton Density-weighted image of the third digit (D). A: Increased signal at the collateral ligaments and synovitis of the proximal interphalangeal (PIP) joint of the third digit (white arrow). Periarticular inflammation around the PIP joint and the body of the proximal phalanx of the third digit (arrowhead). B \& C: Extensive flexor tenosynovitis (asterix) and periarticular inflammation in the subcutaneous tissues (arrowhead) alongside thickened flexor tendon pulleys (arrow). D \& E: Representative sagittal T1-weighted images of the MCP, PIP and DIP joint of the 3rd digit. Following iv contrast administration and appropriate delay of $40 \mathrm{~min}$, A gives the morphologicalT1 map, while B gives the corresponding parameter map with dGEMRIC values [ms] overlaid. Note the significant decrease in dGEMRIC indices of the PIP joint as compared to the MCP joint. changes in cartilage as an imaging biomarker with potential application in detection and monitoring of PsA.

Disclosure of Interests: Philipp Sewerin Grant/research support from: AbbVie Deutschland GmbH \& Co. KG

Bristol-Myers Squibb Celgene $\mathrm{GmbH}$

Lilly Deutschland GmbH

Novartis Pharma GmbH Pfizer Deutschland GmbH

Rheumazentrum Rhein-Ruhr, Consultant of: AMGEN GmbH AbbVie Deutschland $\mathrm{GmbH} \&$ Co. KG Biogen GmbHBristol-Myers Squibb Celgene $\mathrm{GmbH}$ Chugai Pharma arketing Ltd. / Chugai Europe GmbHHexal Pharma Janssen-Cilag$\mathrm{GmbH}$ Johnson \& Johnson Deutschland GmbHLilly Deutschland GmbH / Lilly Europe / Lilly Global Novartis Pharma GmbH Pfizer Deutschland GmbH Roche Pharma Rheumazentrum Rhein-Ruhr Sanofi-Genzyme Deutschland GmbH Swedish Orphan Biovitrum GmbH UCB Pharma $\mathrm{GmbH}$, Speakers bureau AMGEN GmbH AbbVie Deutschland GmbH \& Co. KG Biogen GmbHBristol-Myers Squibb Celgene GmbH Chugai Pharma arketing Ltd. / Chugai Europe GmbHHexal Pharma Janssen-CilagGmbH Johnson \& Johnson Deutschland GmbHLilly Deutschland GmbH / Lilly Europe / Lilly Global Novartis Pharma $\mathrm{GmbH}$ Pfizer Deutschland GmbH Roche Pharma Rheumazentrum Rhein-Ruhr Sanofi-Genzyme Deutschland $\mathrm{GmbH}$ Swedish Orphan Biovitrum GmbH UCB Pharma GmbH, Daniel Abrar: None declared, Sven Nebelung: None declared, Miriam Frenken: None declared, Tim Ulrich: None declared, Karl Ludger Radke: None declared, Gerald Antoch: None declared, Stefan Vordenbäumen: None declared, Ralph Brinks: None declared, Matthias Schneider Grant/research support from: GSK, UCB, Abbvie, Consultant of: Abbvie, Alexion, Astra Zeneca BMS, Boehringer Ingelheim, Gilead, Lilly, Sanofi, UCB, Speakers bureau: Abbvie, Astra Zeneca, BMS, Chugai, GSK, Lilly, Pfizer, Sanofi, Benedikt Ostendorf: None declared, Christoph Schleich: None declared DOI: 10.1136/annrheumdis-2020-eular.5557

\section{OP0183 DO CARTILAGE LAMINAR COMPOSITIONAL CHANGES AS ASSESSED BY T2 RELAXOMETRY PREDICT INCIDENT AND WORSENING OF STRUCTURAL MORPHOLOGIC DAMAGE IN THE SAME PLATE 3 YEARS LATER?}

F. Roemer $^{1,2}$, F. Eckstein ${ }^{3,4}$, G. Duda ${ }^{5}$, S. Maschek ${ }^{3,4}$, A. Guermazi ${ }^{2,6}$, W. Wirth ${ }^{3,4}$. 'Universitätsklinikum Erlangen, Erlangen, Germany; ${ }^{2}$ Boston University, Boston, United States of America; ${ }^{3}$ Paracelsus Medical University, Salzburg, Austria; ${ }^{4}$ Chondrometrics $\mathrm{GmbH}$, Ainring, Germany; ${ }^{5}$ Charité, Berlin, Germany; ${ }^{6}$ VA Boston Healthcare System, Boston, United States of America

Background: To address the question whether laminar changes in knee cartilage T2 are relevant for prediction of lesion onset or progression in the same articular plate we included two different samples from the Osteoarthritis Initiative (OAI) study without radiographic osteoarthritis (ROA), i.e. so-called "healthy controls" with no ROA in either knee and being free of risk factors, and those with $\mathrm{K}-\mathrm{L} 0$ in one knee and ROA in the contralateral knee. Given the concept of the osteochondral unit, we hypothesize that superficial T2 is elevated in cartilage plates with subsequent surface damage development or worsening and deep layer T2 is elevated for those with subsequent bone marrow lesion (BML) development or worsening.

Objectives: To analyze whether knees with subsequent morphologic cartilage and BML development or worsening exhibit elevated cartilage T2 compared to those that do not develop such structural damage in the same plate 3 years later.

Methods: We included 63 knees from the OAI without ROA (K-L 0), but with definite $R O A(K-L \geq 2)$ in the contralateral knee, and 78 participants from the OAI healthy reference cohort.

Cartilage integrity or damage and subchondral bone marrow lesions (BMLs) were assessed for year 1 (i.e. baseline (BL) in this analysis) and year 4 (Y4) in chronological order using the semi-quantitative MOAKS scoring system.

$\mathrm{BL}$ deep and superficial layer cartilage T2 was computed from sagittal multi-echo spin echo MR images. Because cartilage T2 is known to display spatial variation with tissue depth, the segmented cartilages were computationally divided into superficial and deep $50 \%$, based on the distance between the segmented cartilage surface and bone interface. Statistical analyses were performed for the femoro-tibial (FT) joint on a plate level, i.e. medial femur (MF), medial tibia (MT) lateral femur (LF) and lateral tibia (LT), using UNIANOVA with adjustment for age, body mass index, sex, and sample.

Results: 141 participants were included. Of these 79 (56\%) were women, had a mean age of $59.4 \pm 9.1$ years and a mean body mass index of $25.8 \pm 4.1$ $\mathrm{m} / \mathrm{kg}^{2}$.

$52(37 \%)$ had prevalent cartilage lesions in the medial FT joint and $67(48 \%)$ in the lateral FT joint. For BMLs these numbers were 15 (11\%) medially and $14(10 \%)$ laterally. Worsening of FT cartilage lesions from BL to Y4 were seen in $10(7 \%)$ medially and $21(15 \%)$ in the lateral FT compartment. Incident FT cartilage lesions were seen in $11(11.5 \%)$ medially and 8 knees laterally. No worsening BMLs were seen 